\title{
Accuracy of the Corvis Biomechanical Index in Keratoconus Screening
}

\author{
Fazle Hanan ${ }^{1}$, Zulfiqar $\mathrm{Ali}^{2}$, Muhammad Naeem ${ }^{3}$ \\ ${ }^{1}$ Amanat Eye Hospital, Peshawar, ${ }^{2}$ Ayub Medical College, Abbottabad, ${ }^{3}$ Lady Reading Hospital, Peshawar
}

\begin{abstract}
Purpose: To evaluate the accuracy of the Corvis Biomechanical Index (CBI) in screening of patients with Keratoconus.
\end{abstract}

Study Design: Cross sectional study.

Place and Duration of Study: Amanat Eye Hospital Peshawar from July 2018 to June 2019.

Material and Methods: One thousand eyes were included in this study. Patients who came for keratorefractive laser procedure or collagen cross linkage were included in the study by convenient sampling technique. Six hundred and eleven patients had early Keratoconus and 389 were normal controls. Control group included those individuals who had visual acuity of $6 / 6$ with no clinical feature of Keratoconus and normal Tomographic and Biomechanical Index (TBI). All individuals included in the study underwent a thorough ocular examination, CBI and TBI tests. SPSS version 23 was used for statistical analysis of collected data.

Results: The mean $\mathrm{CBI}$ value was $0.3186 \pm 0.407$ standard deviation (SD), the standard error (SE) of the mean was 0.0129 with a $95 \%$ confidence interval $(\mathrm{Cl})$ of 0.293 to 0.343 . The minimum $\mathrm{CBI}$ value was 0.00 and the maximum value was 1.00. The mean Tomographic Biomechanical Index (TBI) value was $0.465 \pm 0.392 \mathrm{SD}, \mathrm{SE}$ was 0.124 with a $95 \% \mathrm{Cl}$ of 0.222 to 0.708 . The range of $\mathrm{TBI}$ values was 0.00 to 1.00 . For $\mathrm{CBI}$, sensitivity was $58.2 \%$, specificity was $100 \%$, positive predictive value was $100 \%$, and negative predictive value was $61.2 \%$.

Conclusion: The current study showed acceptable accuracy of $\mathrm{CBI}$ in terms of specificity and sensitivity. However, the result should be interpreted in combination with clinical data and other topographic and tomographic parameters.

Key Words: Corvis Biomechanical index, Tomographic and Biomechanical index, Belin/Ambrosio enhanced ectasia index.

How to Cite this Article: Hanan F, Ali Z, Naeem M. Accuracy of the Corvis Biomechanical Index in Keratoconus Screening. Pak J Ophthalmol. 2020; 36 (3): 216-220.

Doi: $10.36351 /$ pjo.v36i3.1072

\section{INTRODUCTION}

Identification and exclusion of Forme Fruste Keratoconus prior to any photorefractive procedure is

Correspondence to: Fazle Hanan

Amanat Eye Hospital Peshawar

Email:drfazalhanan@gmail.com

Received: May 28, 2020

Accepted: June 25, 2020

Revised: June 22, 2020 important because it can develop into established Keratoconus after surgery resulting in deterioration of vision. ${ }^{1}$ It is essential that patient should have normal corneal parameters without any suspicion or sign of Keratoconus. Moreover, if early Keratoconus is diagnosed, collagen cross linking can arrest the progression of Keratoconus. ${ }^{2,3,4}$ Keratoconus is a bilateral disease in which there is thinning and steepening of the central and paracentral cornea, appearing around puberty. In early stage, which is also 
called subclinical, Forme Fruste Keratoconus or Keratoconus suspect, the clinical signs are not obvious and the diagnosis can be made with the help of a screening test, which has high degree of sensitivity and specificity ${ }^{5}$.

Different devices are used nowadays for Keratoconus screening, incorporating corneal tomography or pachymetry and topography. These include; Orbscan II $^{6}$ (Bausch \& Lomb, New York, US), Pentacam ${ }^{7}$ (Oculus Optikgeräte $\mathrm{GmbH}$, Wetzlar Germany), Galilei $\mathrm{G}^{8}{ }^{8}$ (Ziemer, Port, Switzerland), and SIRIUS $^{9}$ (CSO, Firenze, Italy). These devices measure corneal curvature, corneal thickness, and elevation of the anterior and posterior corneal surface. Recently, it has been found that changes in biomechanical stability of the cornea precedes topographic and tomographic changes in Keratoconus. ${ }^{10,11}$ To study the biomechanical behavior of cornea, currently used devices are Ocular Response Analyzer R (ORA; Reichert, New York, US) and the Corneal Visualization Scheimpflug Technology Corvis ST; (Oculus Optikgerate GmbH, Wetzlar, Germany).

The ocular response analyzer ${ }^{2}$ determines the corneal hysteresis and the corneal resistance factor. The Corvis ST is a non-contact tonometer with a dual Scheimpflug, high-speed camera that takes more than 4,300 images per second of the central $8 \mathrm{~mm}$ of the cornea in horizontal meridian. The Corvis ST determine the Dynamic Corneal Response (DCR) parameters and the Ambrosio relational thickness (ART). The salient DCR parameters include A1 and A2 velocities, which are the speeds of corneal apex at first and second applanation respectively. The deflection and deformation amplitudes; displacement of corneal apex with reference to the initial state of cornea is the deflection amplitude while the largest displacement of corneal apex in the anterior-posterior direction at the moment of highest concavity is the deformation amplitude which also includes whole eye movement. Deflection amplitude ratio describes the ratio between the deflection amplitude at the apex and the average deflection amplitude measured at 1 or 2 $\mathrm{mm}$ from the center. Similarly, Deformation amplitude ratio describes the ratio between the deformation amplitude at the apex and the average deformation amplitude measured at 1 or $2 \mathrm{~mm}$ from the center. The Delta Arc length describes the change in Arc length during the highest concavity moment from the initial state, in a defined 7-mm zone.

The force balance between the external air pressure and the IOP is determined at first Applanation (A1), which defines the reference position for the stiffness parameter (SP-A1) in the form of force divided by displacement. Therefore, the SP-A1 is defined as resultant pressure (Pr) divided by deflection amplitude at A1.

Ambrósio's Relational Thickness (ARTh) is calculated by first measuring the corneal thickness and the percentage thickness increase relative to the smallest value at points with $0.2 \mathrm{~mm}$ spacing. The ratio between the percentage values (percentage thickness increase) and the corresponding normative values is calculated for each position. The average ratio for all positions provides the Pachymetric Progression Index (PPI). ARTh is finally calculated by dividing corneal thickness at thinnest point with pachymetric progression index. The rationale of the study was to compare the accuracy of CBI in Keratoconus screening with TBI which was taken as the gold standard.

The combination of pachymetric and biomechanical parameters is referred to as tomographic and biomechanical index or $\mathrm{TBI}^{\mathbf{1 2 , 1 3 , 1 4}}$ which has proven to be more accurate than other diagnostic parameters. The purpose of the current study was to evaluate the accuracy of Corvis Biomechanical Index (CBI) in Keratoconus screening by comparing it with TBI.

\section{MATERIAL AND METHODS}

This was a cross sectional study of patients who visited Amanat eye hospital Peshawar between July, 2018 to June 2019. Amanat eye hospital Peshawar is an eye care center providing Keratoconus screening services and laser treatment facilities for patients having refractive errors. The data set included two types of patients; those who were interested in Photorefractive Keratectomy or Femto LASIK treatment for their refractive error or those who were advised Corvis and TBI tests because of the clinical suspicion of Keratoconus in them and hence consideration of collagen cross linkage treatment. These patients were either seen by the consultant of Amanat eye hospital Peshawar, or they were seen and referred by other ophthalmologists for screening purpose.

All those patients who had previous Keratorefractive procedure and those patients who had clinical signs of advanced Keratoconus were excluded. 
The age range was 5 to 50 years and both sexes were included. One thousand eyes of 500 patients were included in the study, out of whom 611 were patients with subclinical or early Keratoconus and 389 were normal controls. Control group included those individuals who had visual acuity of $6 / 6$ with no clinical feature of Keratoconus and normal TBI.

All individuals included in the study underwent a thorough ocular examination, CBI and TBI tests. The devices used for screening were the Oculus Pentacam HR Reference 70900 (Oculus Optikgeräte GmbH, Wetzlar Germany) and the Oculus Corvis ST Reference 72100 (Oculus Optikgerate GmbH, Wetzlar, Germany). The study was conducted while strictly adhering to the study guidelines of the tenets of declaration of Helsinki.

\section{RESULTS}

A total of 1000 eyes of 500 patients were recruited in the study. The number of male and female patients was 318 and 182 with a ratio of 1.747 to 1 respectively. The age range of the patients was 5 to 49 years, with a mean of $21.89 \pm 8.434$ years. 95\% confidence interval for age was $21.151-22.628$ with a standard error of 0.377 years. The cut off ranges for CBI and TBI were 0.00 to 0.25 as normal, 0.26 to 0.5 as suspicious and 0.51 to 1.00 as diseased. The cut off points were similar to those considered by Koh $\mathrm{S}$ and Ambrosio $\mathrm{R} \mathrm{jr}^{15}$ in their study which were $\mathrm{CBI}>0.5$ and $\mathrm{TBI}>0.29$.

The result of CBI in our patients is given in table 1 . The mean CBI value was $0.3186 \pm 0.407$, the

Table 1: Corvis Biomechanical Index.

\begin{tabular}{lcccc}
\hline Category & $\begin{array}{c}\text { Frequency } \\
\text { OD }\end{array}$ & $\begin{array}{c}\text { Frequency } \\
\text { OS }\end{array}$ & Total & \%age \\
\hline Normal & 309 & 326 & 635 & 63.5 \\
Suspicious & 45 & 33 & 78 & 7.8 \\
Diseased & 146 & 141 & 287 & 28.7 \\
Total & 500 & 500 & 1000 & 100 \\
\hline
\end{tabular}

standard error of the mean was 0.0129 with a $95 \%$ confidence interval of 0.293 to 0.343 . The minimum CBI value was 0.00 and the maximum value was 1.00 . The result of TBI is given in table 2 . The mean TBI value was $0.465 \pm 0.392$. The standard error was 0.124 with a $95 \%$ confidence interval of 0.222 to 0.708 . The minimum TBI value was 0.00 and the maximum value was 1.00 .
Table 2: Tomographic Biomechanical Index.

\begin{tabular}{lcccc}
\hline Category & $\begin{array}{c}\text { Frequency } \\
\text { OD }\end{array}$ & $\begin{array}{c}\text { Frequency } \\
\text { OS }\end{array}$ & Total & \% age \\
\hline Normal & 192 & 197 & 389 & 38.9 \\
Suspicious & 114 & 113 & 227 & 22.7 \\
Diseased & 194 & 190 & 384 & 38.4 \\
Total & 500 & 500 & 1000 & 100 \\
\hline
\end{tabular}

Table 3: Evaluation of CBI comparing it with TBI.

\begin{tabular}{|c|c|c|c|}
\hline CBI Result & Disease Present & Disease Absent & Total \\
\hline $\begin{array}{l}\text { Positive test } \\
\text { (suspicious plus } \\
\text { diseased) }\end{array}$ & 365 (true positive) & 0 (false positive) & 365 \\
\hline Negative test & $\begin{array}{l}246 \text { (false } \\
\text { negative) }\end{array}$ & $\begin{array}{l}389 \text { (true } \\
\text { negative) }\end{array}$ & 635 \\
\hline Total & 611 & 389 & 1000 \\
\hline
\end{tabular}

Sensitivity $=58.2 \%$

Specificity $=100 \%$

Positive predictive value $=100 \%$

Negative predictive value $=61.2 \%$

Table 4: CBI Vs TBI ( $p$ Value Calculation).

\begin{tabular}{lllr}
\hline & $\begin{array}{l}\text { CBI Observed } \\
\text { (Expected) }\end{array}$ & $\begin{array}{l}\text { TBI Observed } \\
\text { (Expected) }\end{array}$ & Total \\
\hline $\begin{array}{l}\text { Normal } \\
\begin{array}{l}\text { Suspicious } \\
\text { plus diseased }\end{array}\end{array}$ & $635(512)$ & $389(512)$ & 1024 \\
$\begin{array}{l}\text { Total } \\
\text { (observed) }\end{array}$ & 1000 & $611(488)$ & 976 \\
\hline
\end{tabular}

Chi square value $=29.5$

Degree of freedom $=1$

$\mathrm{p}$ value $=\square 0.001$

\section{DISCUSSION}

In Keratoconus, cornea is soft and thin. Scarcelli ${ }^{11}$ suggested that as the effect of strain is more on the softer area of the cornea, intraocular pressure and external factors such as eye rubbing cause softer area of the cornea to bulge out and become thin to redistribute the effect of strain. Corneal bulging results in focal reduction in stress as a compensatory mechanism resulting in a vicious circle of straining, bulging and thinning.

The data available in literature does not prove to be definitive in diagnosing Keratoconus as there is a considerable overlap between normal corneas and Forme Fruste Keratoconus ${ }^{16,17}$. In this study, we compared the accuracy of CBI in Keratoconus screening by calculating their sensitivity and specificity against TBI from the collected data and their positive and negative predictive value. 
In the current study, sensitivity and specificity of CBI was $58.2 \%$ and $100 \%$ respectively. The positive and negative predictive value of CBI was $100 \%$ and $72.3 \%$ respectively. In the study of Vinciguerra et $\mathrm{al}^{18}$, the sensitivity of CBI was found to be $94.1 \%$ and specificity of $100 \%$. The reason for the higher sensitivity in that study was that they compared the results of normal individuals with those having established Keratoconus whereas our study included Forme Fruste Keratoconus, in which diagnosis is more difficult and challenging.

However, Wang et al $^{19}$ in his study described sensitivity and specificity of CBI in Forme Fruste Keratoconus as $63.2 \%$ and $80.3 \%$ respectively. The reason for the lower specificity of CBI in that study might be the comparison of subclinical Keratoconus with normal population whereas we compared both subclinical and early established Keratoconus cases with normal cases.

The difference between the results of different studies is due to the observation ${ }^{20}$ that the discriminatory power of these indices decreases in the following order a) comparing normal eyes with established Keratoconus. b) comparing normal eyes with early Keratoconus in which the opposite eye of the patient has normal topography. c) comparing normal eyes with subclinical Keratoconus in which the opposite eye has both normal topography and tomography.

This data show CBI was highly specific, which means that its positive result is reliable. However, this index has acceptable sensitivity, which may imply the possibility of false negative results in subclinical Keratoconus at early stage. If a patient is labeled negative with CBI and there is clinical suspicion of Forme Fruste Keratoconus, the test should be interpreted in combination with other parameters such as BAD-D, TBI, mean keratometry, index of vertical asymmetry and index of surface variance.

Applying the chi square statistics, the $p$ value of the comparison of the two tests is $\square 0.001$, which is due to the presence of significant number of false negative $\mathrm{CBI}$ results.

Limitation of the study is that the study was done at a single center. Further data from other centers is required to support our results.

\section{CONCLUSION}

The result of CBI should be interpreted in combination with other topographic, tomographic and topometric parameters such as BAD_D, TBI, mean keratometry, index of surface variance and index of vertical asymmetry.

\section{Ethical Approval}

The study was approved by the Institutional review board/Ethical review board.

\section{Conflict of Interest}

Authors declared no conflict of interest.

\section{Authors' Designation and Contribution}

Fazle Hanan; Associate Professor: Study concept and design, data collection, analysis and interpretation of data, writing the manuscript, critical revision, supervision.

Zulfiqar Ali; Associate Professor: Analysis and interpretation of data, critical revision.

Muhammad Naeem; Assistant Professor: Analysis and interpretation of data, critical revision.

\section{REFERENCES}

1. Spadea L, Cantera E, Cortes M, Conocchia NE, Stewart CW. Corneal ectasia after myopic laser in situ keratomileusis: a long-term study. Clin Ophthalmol. (Auckland, NZ). 2012; 6: 1801.

2. Vinciguerra R, Ambrósio R, Elsheikh A, Roberts CJ, Lopes B, Morenghi E, et al. Detection of Keratoconus with a new biomechanical index. J Refract Surg. 2016; 32 (12): 803-10.

3. Alhayek A, Lu PR. Corneal collagen cross linking in Keratoconus and other eye disease. Intern J Ophthalmol. 2015; 8 (2): 407.

4. Meiri Z, Keren S, Rosenblatt A, Sarig T, Shenhav L, Varssano D. Efficacy of corneal collagen cross-linking for the treatment of Keratoconus: a systematic review and meta-analysis. Cornea. 2016; 35 (3): 417-28.

5. Kymionis GD, Siganos CS, Tsiklis NS, Anastasakis A, Yoo SH, Pallikaris AI, et al. Long-term follow-up of Intacs in Keratoconus. Am J Ophthalmol. 2007; 143 (2): 236-44.

6. Wei RH, Zhao SZ, Lim L, Tan DT. Incidence and characteristics of unilateral Keratoconus classified on corneal topography. J Refract Surg. 2011; 27 (10): 74551. 
7. Bae GH, Kim JR, Kim CH, Lim DH, Chung ES, Chung TY. Corneal topographic and tomographic analysis of fellow eyes in unilateral Keratoconus patients using Pentacam. Am J Ophthalmol. 2014; 157 (1): 103-9.

8. Golan O, Piccinini AL, Hwang ES, Gonzalez IM, Krauthammer M, Khandelwal SS, et al. Distinguishing Highly Asymmetric Keratoconus Eyes Using Dual Scheimpflug/Placido Analysis. Am J Ophthalmol. 2019; 201: 46-53.

9. Bayramoğlu SE, Sayın N, Ekinci DY, Erdoğan M. Comparison of Keratometry, Central Corneal Thickness, and Anterior Chamber Depth Results Measured With Nidek-AL Scan Biometry and Sirius Topography Devices. Istanb Med Journal. 2018; 19 (2): 158-61.

10. Ambrósio R Jr, Dawson DG, Salomão M, Guerra FP, Caiado AL, Roberts CJ. Biomechanics in Keratoconus. In: Barbara A, ed. Textbook of Keratoconus: New Insights, 1st ed. New Delhi: Jaypee Brothers Medical Publishers; 2012: 29-32.

11. Scarcelli G, Besner S, Pineda R, Yun SH. Biomechanical characterization of Keratoconus corneas ex vivo with Brillouin microscopy. Invest Ophthalmol Vis Sci. 2014; 55: 4490-4495.

12. Salomão MQ, Hofling-Lima AL, Gomes Esporcatte LP, Lopes B, Vinciguerra $R$, Vinciguerra $P$, et al. The Role of Corneal Biomechanics for the Evaluation of Ectasia Patients. Int J Environ Res Public Health. 2020; 17 (6): 2113.

13. Kataria $\mathbf{P}$, Padmanabhan $\mathbf{P}$, Gopalakrishnan A, Padmanaban V, Mahadik S, Ambrósio Jr R. Accuracy of Scheimpflug-derived corneal biomechanical and tomographic indices for detecting subclinical and mild keratectasia in a South Asian population. J Cataract Refract Surg. 2019; 45 (3): 32836.

14. Ferreira-Mendes J, Lopes BT, Faria-Correia F, Salomão MQ, Rodrigues-Barros S, Ambrósio Jr R. Enhanced ectasia detection using corneal tomography and biomechanics. Am J Ophthalmol. 2019; 197: 7-16.

15. Koh S, Ambrosio R Jr, Inoue R, Maeda N, Nishida K. Detection of subclinical corneal ectasia using corneal tomographic and biomechanical assessment in Japanese population. J Refract Surg. 2019; 35 (6): 383 390.

16. Ortiz-Toquero S, Martin R. Keratoconus screening in primary eye care-A general overview. Eur Ophth. 2016; 10 (2): 80-5.

17. Hashemi H, Beiranvand A, Yakta A, Maleki A, Yazdani N, Khabazkhoob M. Pentacam top indices for diagnosing subclinical and definite Keratoconus: J Curr Ophthalmol. 2016; 28 (1): 21-26.

18. Vinciguerra R, Ambrosio R Jr, Elsheikh A, Roberts JC, Lopes B, Morenghi E, et al. Detection of Keratoconus with a new biomechanical index: J Refract Surg. 2016; 32 (12): 803-810.

19. Wang YM, Chan TCY, Yu M, Jhanji V. comparison of corneal dynamic and tomographic analysis in normal, forme fruste Keratoconus, and keratoconic eyes: J Refract Surg. 2017; 33 (9): 632-638.

20. Steinberg J, Siebert M, Katz T, Frings A, Mehlan J, Druckiv V, et al. Tomographic and biomechanical Scheimpflug imaging for Keratoconus characterization: a validation of current indices. Journal of Refractive Surgery. 2018; 34 (12): 840-7. 